\title{
An Evaluative Study on the Choice of Regional Strategic Emerging Industry Based on DEMATEL: Heilongjiang Province as an Example
}

\author{
Xiuying Guo, ${ }^{1,2}$ Xiaofeng Hui, ${ }^{1}$ and Junxiang Wang ${ }^{2}$ \\ ${ }^{1}$ School of Management, Harbin Institute of Technology, Harbin, Heilongjiang 150001, China \\ ${ }^{2}$ College of Mathematics, Heilongjiang Institute of Technology, Harbin, Heilongjiang 150050, China \\ Correspondence should be addressed to Xiuying Guo; guoxiuying6@163.com
}

Received 29 March 2013; Accepted 22 May 2013

Academic Editor: Tingwen Huang

Copyright ( $\odot 2013$ Xiuying Guo et al. This is an open access article distributed under the Creative Commons Attribution License, which permits unrestricted use, distribution, and reproduction in any medium, provided the original work is properly cited.

Currently, the convergence of choosing regional strategic emerging industry is very serious in our country. And affected by its developmental stage, at present, the research of the methodology for choosing and evaluating regional strategic emerging industry is not very mature and lacks systematic and dynamic study. By expanding the DEMATEL method to the field of the complex weighted network, comparing the regional industry to a dynamic system and establishing the DEMATEL improved model based on industry input-output table, it is possible to realize the systematicness and dynamic nature of choosing regional strategy emerging industry.

\section{Introduction}

Throughout the history, the economic crisis will promote the development of emerging industries every time, and in various countries around the world, the emerging industries are of strategic importance to deal with the financial crisis, construct the new economical growth point, and preempt the development opportunities of the future. In September, 2009, Premier Jiabao Wen presided over three forums about strategic emerging industry development and "the concept of strategic emerging industry" was proposed for the first time. In October, 2010, the State Council determined seven industries as strategic emerging industries in China: energy conservation and environment protection, new generation of information technology, biotechnology, high-end equipment manufacturing, new energy, new materials, and alternative fuel vehicles. In March, 2012, Premier Jiabao Wen emphasized in the "government work report," to further promote the healthy development of strategic emerging industries, promoting the optimization and upgrading of industrial structure [1].

At present, strategic emerging industry has entered a stage of deepening development, which means, as the core of all levels of local government, establishing regional strategic emerging industries and overall promoting the upgrading of regional industrial structure and then promoting the sustainable development of social economy. Due to the economic development level of various regions in China and resource endowments have differences, regional industrial structure has its own characteristics, and its industrial gradual progress has obvious regional characteristics [2]. Therefore, regional practice must first be selected scientifically before regional strategic emerging industry will be developed. At present, led by the planning of country strategic emerging industry, proceeding from the separate condition, advantage, and characteristic, the provinces (cities, regions) of our country propose the strategic emerging industry planning during the period of "12th Five-Year Plan." However, after sorting out the strategic emerging industry planning in thirty provinces (cities, regions) of our country, the author found that during the period of "12th Five-Year Plan," the convergence in the choice of the regional strategic emerging industries is very serious, as shown in Figure 1.

The number of region selecting new material is twentynine, the region selecting new energy is twenty-six, the number of selecting biological is twenty-five; these three ones are ranked as the top three. The convergence in the 


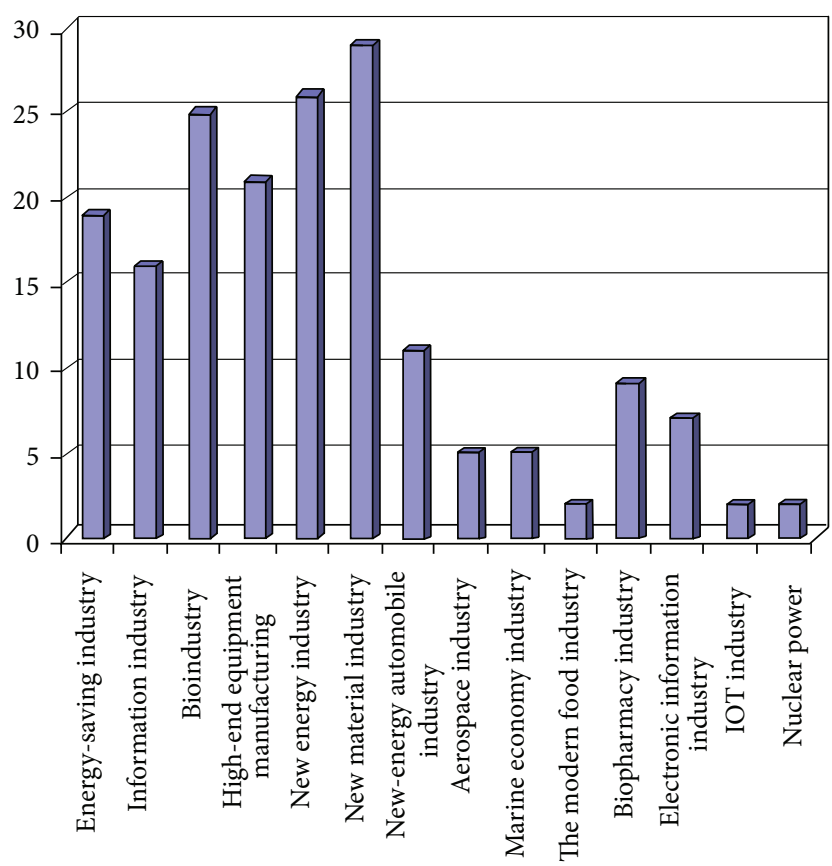

The number of districts

FIGURE 1: Selected case charts of the strategic emerging industry in thirty provinces (cities) of our country.

choice of the regional strategic emerging industries can easily result in vicious competition, redundant construction, waste of resources, and other issues of excess production capacity. Regional strategic emerging industry is never a simple regional of the country strategic emerging industries, the difference between the two is not only in amount, but also in quality. Therefore, how to accurately and scientifically select and evaluate the regional strategic emerging industry will have important theoretical and practical meanings.

At present, many scholars are carrying on the theoretical and empirical research of the strategic emerging industries: first, Qiao and Yang [3] and Xiong and Zeng [4] established an evaluation system from the perspective of coupling the emerging industries and traditional industries. Second, $\mathrm{He}$ [5], $\mathrm{Li}$ [6], and Luo [7] and $\mathrm{Hu}$ et al. [8] constructed the choice model based on the Analytic Hierarchy Process (AHP), fuzzy comprehensive and the combination of "AHPIE-PCA" empowerment evaluation method. Third, Liu and Cheng [9] and Liu [10] used comparative analysis to propose the suggestion of choosing mechanism. Forth, Ao and Liu [11] come up with the choosing principle, basic principle and several kinds of typical selective methods of the strategic emerging industry from the theoretical level.

It is not difficult to see that scholars for regional strategic emerging industry choice mainly focused on the importance of strategic emerging industry, connotation and characteristic, mechanism of formation and development, selection principle, and cultivation measures discussion of theory; empirical research is mainly to have a set of strategic emerging industries evaluation of each area; method is selection the method of simple transplantation for leading industry, lacking regional strategic emerging industry choice and the choice of system science method and evaluation system. As regional industrial system is a complicated dynamic system, and strategic emerging industry has strong correlation effect and characteristics of sustainable development, this paper will be based on the complicated network and input-output theory, with the aid of DEMATEL improved model as an example to Heilongjiang province regional strategic emerging industry selection research, and will do dynamic gathered qualitative research for selection result.

\section{The Choice of Regional Strategic Emerging Industry Based on the Improved DEMATEL Model}

2.1. Industrial Complex Network and the Introduction of the Theory of Input and Output. Regional industrial system, being the most complicated subsystem of national economic system construction, must composite complex system theory and macroeconomic quantity analysis to make overall planning [12]. Industrial system is mainly related to the input and output of the interindustry; so with the help of the input and output theory, we need the theory of input and output to study some characteristics of the regional industrial system. Inputoutput theory is founded by the Harvard University professor Wassily Leontief in 1936, and it mainly studies the quantitative analysis of the input-output interdependence relationship of each part in the economic system. This interindustry perplexing relationship of supply and demand generally is succinctly explained by the input-output table.

\subsection{Based on DEMATEL Improved Model of the Input-Output} Table and Empirical Research. DEMATEL is an analysis method, using graph theory and matrix tools for system analysis, proposed by the American scholar Gabus and Fontela. By constructing the direct affect matrix between system factors, apply the matrix to calculate the center degree and reason degree of each factor, and then determine the importance of various factors in the system. This method is more effective for dealing with complicated social economic problems, especially for the problem of unclear relationships of system factor [13]. In recent years, many scholars apply DEMATEL to study complex system. Tzeng et al. [14] use DEMATEL, structure analysis method (AHP), and fuzzy integral to construct a selection evaluation model of online learning project. Liang and $\mathrm{Ma}$ [15] apply DEMATEL method to analyze the foundation engineering construction risk. Zhu and Yang [16] bring DEMATEL and entropy according to the autocorrelation of customers' demand and the influence of market competition evaluation to correct the basic important factor of the customers' needs and integrate the processing results of the two sides, then we can get more objective final important factor of the customers' needs.

On the basis of using DEMATEL method for reference, this paper extends the DEMATEL method to the weighted field of complex network, confirms network supporting matrix using the improved DEMATEL method, studies the 
relations of every industrial department based on inputoutput matrix, then determines the preselected strategic emerging industry whose centrality and reason degree are high. The DEMATEL improved model based on complex network is described as follows.

Step 1. Generated standardized effect matrix $D$.

We regard every industrial department of the national economy as one point and regard input-output relationship of each department as one border. Take, for example, inputoutput table of 42 industry departments of Heilongjiang province in 2007, we regard each industry department as an influencing factor and regard the input and output values of every industrial departments as weighted interrelation between every factor, $a_{i j}$, and get direct affect matrix $A=$ $\left(a_{i j}\right),(i, j=1,2, \ldots, 42)$. By setting up the table of 42 industrial departments corresponding to sequence number, as shown in Table 1, we represent the industry name with sequence number in the latter research.

According to the direct affect matrix $A$, with the help of

$$
D=s A \quad(s>0),
$$

construct standardized affect matrix $D$, where $d_{i j}=s a_{i j}$, $(i, j=1,2, \ldots, N)$ and " $S$ " is called the scale factor, $0<S<$ Sup. We usually make

$$
\operatorname{Sup}=\max \left\{\frac{1}{\max _{1 \leq i \leq N} \sum_{j=1}^{N}\left|a_{i j}\right|}, \frac{1}{\max _{1 \leq j \leq N} \sum_{i=1}^{N}\left|a_{i j}\right|}\right\} .
$$

According to (1) and (2) calculation methods, we use MATLAB 7.1 to calculate the ratio factor of Heilongjiang province standardization impact matrix $D s=7.65036819+$ $E-9$ and get the standardized affect matrix $D$.

Step 2. Construct total impact matrix $T$.

The sum of rows of matrix $D$ is called the outgoing degree of $i$ industry, which expresses the direct impact total intensity of the industry $i$, as $d_{i}^{\text {out }}=\sum_{j=1}^{N} d_{i j}$. The sum of columns of matrix $D$ column is called incoming degree of industry $j$, which expresses the direct impact total intensity of the industry $j$, as $d_{j}^{\text {in }}=\sum_{j=1}^{N} d_{i j}$. However, for the actual issue, we not only consider the direct effect between the industries, but we also need to consider the indirect effects between the industries, and the chain effects brought by an industry change. The total effect matrix $T$ expresses the comprehensive summation of the direct and indirect effects between factors, in order to determine the final effect of each factor relative to the highest level factor in the system. That is,

$$
\begin{gathered}
T=C+C^{2}+\cdots+C^{n}=C \frac{I-C^{n-1}}{I-C} . \\
\text { Since } 0 \leq C_{i j} \leq 1 \text {, so, when } n \rightarrow \infty, C^{n-1} \rightarrow 0, \\
T=C \frac{I}{I-C}=C(I-C)^{-1} .
\end{gathered}
$$

TABLE 1: The table of 42 industries of national economy in Heilongjiang province corresponding to sequence number.

Industrial sequence $\quad$ Industry name
number

\section{1}

2

3

4

5

6

7

8

9

10

11
Agriculture forestry, animal husbandry

Coal mining and coal washing industry Oil and natural gas industry Metal mines

Nonselected industry

Food manufacturing and tobacco processing

Textile crafts and others

Textile, leather, and products industry

Wood processing and furniture manufacturing industry

Paper printing and stationery and sports goods manufacturing industry

Petroleum processing, coking, and nuclear fuel processing The chemical industry

Nonmetallic mineral products industry Metal smelting and rolling processing industry

Metal products industry General, special equipment manufacturing industry

Transportation equipment manufacturing Electrical machinery

Equipment manufacturing industry in communications equipment, computers, and other electronic equipment metal mine and other mining manufacturing instrumentations and cultures

Office machinery manufacturing industry Manufacturing and others Waste

Electricity, heat production and supply industry

Gas production and supply industry

Water production, and supply industry Construction

Transportation and warehousing industry Postal industry

Information transmission, computer service, and software industry

Wholesale and retail trade industry

Accommodation and catering industry

Finance and insurance industry Real estate

Leasing and business services Tourism

Research and experimental development industry

Integrated technology services Other social services Education

Health, social security, and social welfare Culture, sports, and entertainment industry

Public management and social organization 
TABLE 2: The table of 42 industries impacted degree in Heilongjiang province in 2007.

\begin{tabular}{|c|c|}
\hline Industrial serial number & Impact degree \\
\hline 1 & 0.95071 \\
\hline 2 & 0.30522 \\
\hline 3 & 0.9977 \\
\hline 4 & 0.095245 \\
\hline 5 & 0.04165 \\
\hline 6 & 0.42161 \\
\hline 7 & 0.037194 \\
\hline 8 & 0.035844 \\
\hline 9 & 0.087075 \\
\hline 10 & 0.11412 \\
\hline 11 & 0.71392 \\
\hline 12 & 0.75186 \\
\hline 13 & 0.13191 \\
\hline 14 & 0.67531 \\
\hline 15 & 0.13036 \\
\hline 16 & 0.58628 \\
\hline 17 & 0.15669 \\
\hline 18 & 0.23295 \\
\hline 19 & 0.079387 \\
\hline 20 & 0.095469 \\
\hline 21 & 0.017872 \\
\hline 22 & 0.025863 \\
\hline 23 & 0.66337 \\
\hline 24 & 0.014136 \\
\hline 25 & 0.046386 \\
\hline 26 & 0.059348 \\
\hline 27 & 0.62216 \\
\hline 28 & 0.049898 \\
\hline 29 & 0.11265 \\
\hline 30 & 0.52904 \\
\hline 31 & 0.13655 \\
\hline 32 & 0.18218 \\
\hline 33 & 0.096514 \\
\hline 34 & 0.15404 \\
\hline 35 & 0.008932 \\
\hline 36 & 0.031676 \\
\hline 37 & 0.014577 \\
\hline 38 & 0.12878 \\
\hline 39 & 0.021051 \\
\hline 40 & 0.029709 \\
\hline 41 & 0.027365 \\
\hline 42 & 0.001848 \\
\hline
\end{tabular}

According to the formula in (4), after calculation, we can get the total effect matrix Tof 42 industries of Heilongjiang province in 2007.

Step 3. Calculate the impacted degree matrix $T_{r}$ and the affected degree matrix $T_{c}$.
The row sum and column sum of sum-impact matrix $T$ are known as the impact matrix $T_{r}$ and the affected matrix $T_{c}$, thereinto,

$$
\begin{aligned}
& T_{r}(i)=\sum_{j=1}^{n} t_{i j}, \\
& T_{c}(j)=\sum_{i=1}^{n} t_{i j} .
\end{aligned}
$$

By the formula in (5), we calculated the impact degree of 42 industries of Heilongjiang province in Table 2, affected degree of 42 industries of Heilongjiang province in Table 3.

Step 4. Calculate centrality degree matrix $M$ and reason degree matrix $R$.

The impact matrix $T_{r}$ plus the affected matrix $T_{c}$ is the centrality degree matrix $M$, namely,

$$
M=T_{r}+T_{c}
$$

$M_{i}$ is the centrality degree of $i$ th industry, representing the importance of $i$ th industry in regional industrial system, namely,

$$
M_{i}=T_{r}(i)+T_{c}(i)
$$

The impacted matrix $T_{r}$ minus the affected matrix $T_{c}$ is the reason degree matrix $R$, namely,

$$
R=\left(T_{r}-T_{c}\right)
$$

$R_{i}$ is the reason degree of $i$ th industry, which represents causes or results of $i$ th industry in input-output process of the industrial system factors, namely,

$$
R_{i}=T_{r}(i)-T_{c}(i)
$$

If the reason degree $R_{i}>0$, then it shows that the $i$ th industry is more influential than other industries, and the industry $i$ is reason industry; if the reason degree $R_{i}<0$, then it shows that the $i$ th industry is more affected than other industries, and the industry $i$ is called the outcome industry. By the formula in (6) and (8), we calculate the top 10 industrial centrality degrees in Table 4 and the reason degree table of the corresponding industry in Table 5.

Step 5. Draw industry cause-result diagram.

First, establish Descartes coordinate system by the centrality degree to be the abscissa and the reason degree to be the ordinate. Second, mark the position of the industry in the coordinate system in Figure 2. Third, choose the strategic emerging industry according to the centrality degree and reason degree to analyze the various roles of the industries in the regional industry system, and give some suggestions to the actual industrial system. 
TABLE 3: The table of 42 industries affected degree in Heilongjiang province in 2007.

\begin{tabular}{|c|c|}
\hline Industrial serial number & Affected degree \\
\hline 1 & 1.0523 \\
\hline 2 & 0.1989 \\
\hline 3 & 0.2731 \\
\hline 4 & 0.014714 \\
\hline 5 & 0.021051 \\
\hline 6 & 1.1157 \\
\hline 7 & 0.048682 \\
\hline 8 & 0.069762 \\
\hline 9 & 0.11041 \\
\hline 10 & 0.08791 \\
\hline 11 & 0.81487 \\
\hline 12 & 0.58536 \\
\hline 13 & 0.11039 \\
\hline 14 & 0.19893 \\
\hline 15 & 0.076224 \\
\hline 16 & 0.50038 \\
\hline 17 & 0.24168 \\
\hline 18 & 0.12866 \\
\hline 19 & 0.018562 \\
\hline 20 & 0.025923 \\
\hline 21 & 0.010428 \\
\hline 22 & 0.004718 \\
\hline 23 & 0.59301 \\
\hline 24 & 0.016373 \\
\hline 25 & 0.037949 \\
\hline 26 & 1.2815 \\
\hline 27 & 0.40812 \\
\hline 28 & 0.056323 \\
\hline 29 & 0.076689 \\
\hline 30 & 0.2504 \\
\hline 31 & 0.2205 \\
\hline 32 & 0.076427 \\
\hline 33 & 0.10506 \\
\hline 34 & 0.10007 \\
\hline 35 & 0.020194 \\
\hline 36 & 0.025845 \\
\hline 37 & 0.033515 \\
\hline 38 & 0.15067 \\
\hline 39 & 0.12273 \\
\hline 40 & 0.17842 \\
\hline 41 & 0.025338 \\
\hline 42 & 0.12669 \\
\hline
\end{tabular}

2.3. The Analysis of DEMATEL Results and the Suggestion of Strategic Emerging Industry Selection. As Table 2 shows, $0.001848 \leq T_{r}(i) \leq 0.9977$, the expected value is 0.228915 and the standard deviation is 0.281140 . Among these data,

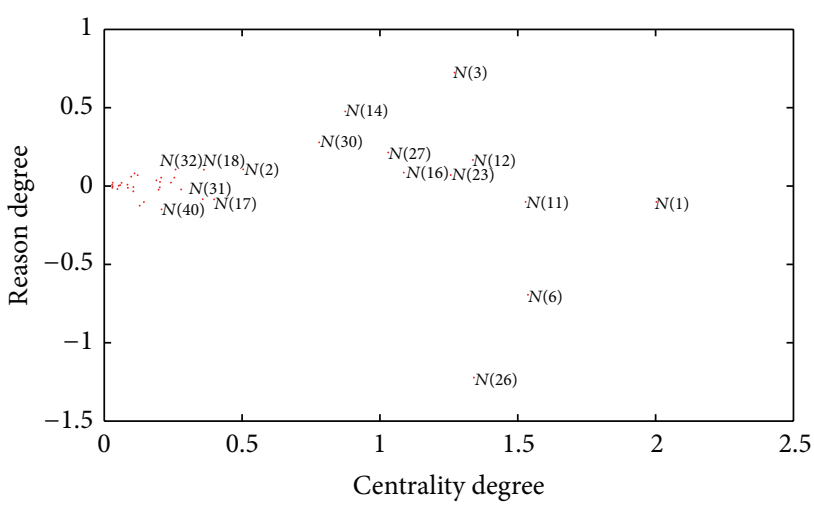

FIgURE 2: The cause-result diagram of 42 industries in Heilongjiang province.

the largest impacted degree is oil and natural gas exploitation industry, followed by agriculture, hunting, and chemical industry. We can see that the industry influenced degree of Heilongjiang province is less than 1, but the standard deviation is relatively large, which means Heilongjiang Province industrial agglomeration level is low and the distribution of industries is scattered. Agriculture and energy industries are the two major industries of Heilongjiang province.

As Table 3 shows, $0.004718 \leq T_{c}(j) \leq 1.2815$, the expected value is 0.228916 and the standard deviation is 0.315526 . We can see that the standard deviation of industrial impacted degree is larger than the industrial affected degree, that is, to say, the affected degree varies greatly. Food manufacturing and tobacco processing industry, animal husbandry, and fishery are rounding out the top three industries impacted degree, and they are mainly concentrated in primary industry and secondary industry.

As Table 4 shows, $0.0283 \leq M_{i} \leq 2.00301$, Heilongjiang province's industry centrality degree is low, lacking the core industry in region system. The centrality degree industries such as agriculture, hunting, petroleum processing, coking and nuclear fuel processing, transportation, and warehousing industries are more larger and can be taken as the development base of strategic emerging industry for their comprehensive influence in Heilongjiang province.

As Table 5 shows, the reason degrees of 24 industries are positive values, $0.002027 \leq R_{i} \leq 0.7246$. They become the reason factors to influence the development of other industries. The top 2 of 24 industries impacted degree including oil and natural gas industry and metal smelting and rolling processing industry which have more influence than other industries are the cause of industry. And the reason degrees of 24 industries are negative values, $-0.124842 d \leq$ $R_{i} \leq-0.002237$. The last 2 of 18 industries impacted degree including construction industry and food manufacturing and tobacco processing industry which are affected more largely by other industries are the result industry. This kind of industry departments should put more attention to the development and changes of their related industries and adjust their development strategies timely.

In view of the above analysis, the higher degree of influence in Heilongjiang Province mainly comprises agriculture, 
TABLE 4: The table of top 10 industries centrality degree in Heilongjiang province in 2007.

\begin{tabular}{lcc}
\hline Industry number & Industry name & Centrality \\
\hline 1 & Agriculture forestry animal husbandry, and fishery & 2.003 \\
6 & Food manufacturing and tobacco processing & 1.5373 \\
11 & Petroleum processing, coking, and nuclear fuel processing & 1.5288 \\
26 & Construction & 1.3408 \\
12 & The chemical industry & 1.3372 \\
3 & Oil and natural gas industry & 1.2708 \\
23 & Electricity, heat production, and supply industry & 1.2564 \\
16 & General special equipment manufacturing industry & 1.0867 \\
27 & Transportation and warehousing industry & 1.0303 \\
14 & Metal smelting and rolling processing industry & 0.87424 \\
\hline
\end{tabular}

TABLE 5: The table of reason degree in Heilongjiang province in 2007 (the top 10 industries centrality degree).

\begin{tabular}{lcc}
\hline Industry number & Industry name & Reason degree \\
\hline 1 & Agriculture forestry, animal husbandry, and fishery & -0.10156 \\
6 & Food manufacturing and tobacco processing & -0.69412 \\
11 & Petroleum processing, coking, and nuclear fuel processing & -0.10095 \\
26 & Construction & -1.2221 \\
12 & The chemical industry & 0.1665 \\
3 & Oil and natural gas industry & 0.72461 \\
23 & Electricity, heat production, and supply industry & 0.07036 \\
16 & General special equipment manufacturing industry & 0.085897 \\
27 & Transportation and warehousing industry & 0.21404 \\
14 & Metal smelting and rolling processing industry & 0.47637 \\
\hline
\end{tabular}

forestry, animal husbandry and fishery, oil and equipment manufacturing. Therefore, for Heilongjiang province, on the basis of international and domestic scientific and technological progress and industrial development objective trends to be taken full advantage of, the primary industry and the advantages of the secondary industry should be given full play, from the specific situation in Heilongjiang province, combined with the major needs of the current economic and social development; the strategic emerging industry selection should be determined. Specific recommendations are as follows.

(1) Relying on the centrality, the agriculture, forestry, animal husbandry, and fisheries would be ranked first, in Heilongjiang province; bioindustry and farm machinery and equipment manufacturing industry can be an important part of the strategic emerging industries. There are 200 million mu of arable land in Heilongjiang province and is the country's total arable land ninth, and it is one of the most important grain production bases in China. However, in Heilongjiang Province, there is still raw grain economy and the agricultural lack of scientific and technological content and industrial innovation. Therefore, the resource advantages of agriculture should be given full play, in order to accelerate the upgrading of industrial structure of agriculture, to strengthen the deepening agricultural production processing and development of upstream and downstream biological industry chain, and vigorously to develop green products, the formation of the ecological cycle of bioclusters. At the same time, in Heilongjiang province, the agricultural investment in the equipment manufacturing industry should be further strengthened, to make their own province of farm machinery and equipment manufacturing industry and to gradually realize the industrialization of agriculture, ultimately the formation of the organic combination of TIAC.

(2) Relying on the degrees of the reasons, mining industry on oil and natural gas, as well as electric power, the heat production and the supply industry ranked in first number, in Heilongjiang province, the led "oil economy" should be changed gradually; the formation of a new pattern of wind energy, hydropower, biomass, and other new types of clean energy-based diversified energy development should be formed. Carry out the riding implementation strategies, and develop with the large-scale backbone enterprises. Based on the straight play of the leading role of large enterprise, the upgrading of the energy industry should be promoted accelerately. Actively participate in the restructuring and industrial upgrading of the central enterprises, do a good job to build together and to form a complete set, explore together with the central enterprises to form the diversification of the new energy industry base and industrial base so as to realize the transformation of economy of the resource-based cities, especially the resource-exhausted cities.

(3) Rely on the common use in the higher central degrees and causes of them, and also depend on the special equipment 
manufacturing, actively seize the chances of the policy in the aircraft, rail transportation and automobile industry. In Heilongjiang Province we should focus on the manufacturing industry of the construction of the transportation equipment. There is a good base on transportation equipment manufacture in Heilongjiang province; Dongan group has become a major research and production base for aviation engine and helicopter transmission system; there are, 4G1 and 4G9, two series engine manufacturing technology and products in the automobile engine company of Dong' an; there are four production bases in North car group with Qi, Ha, Mu, and $\mathrm{Da}$, and there is the e-design manufacturing and export base of railway freight and railway cran of China, and the domestic market share is more than $20 \%$.

(4) In the mining province, there are varieties of mineral resources abundant in Heilongjiang province. Now, 134 kinds of minerals of various kinds have been discovered, accounting for $57.2 \%$ of the 234 kinds of various minerals that have been found in China. There are 87 species that have been identified reserves of mineral, and it has been identified that there are 87 kinds of mineral reserves, accounting for $37.7 \%$ of the number of the resources of the mineral reserves. Therefore, the new material industry may be taken as strategic emerging industry in Heilongjiang province, which has important strategic significance for promoting the upgrading of industrial structure and transformation of economic development.

In January 2011, "Heilongjiang Province National Economic and Social Development 12th Five-Year Plan" is proposed by the Heilongjiang Provincial Party Committee; the synopsis to develop new materials industry, biological industry, new energy equipment manufacture, new farm machinery and equipment manufacturing, transportation equipment manufacturing industry, and five strategic emerging industries is pointed out clearly, and it is consistent with the strategic emerging industry in this paper.

\section{The Cluster Analysis of Regional Emerging Industries}

The cultivation of strategic emerging industry cluster is an important way develop regional economic transformation and industrial upgrading, so, we should appraise the standard of strategic emerging industry accumulation dynamically after we have chosen and determined the strategic emerging industries.

It is important to give the major construction to the strategic emerging industries which have good aggregation and form regional leading and characteristic industry by excavating their upstream and downstream industries. This action will drive the regional economic development. In addition, it is equally important to analyze the reasons of the strategic emerging industries which have poor aggregation and realize the reasonable distribution.

3.1. Analysis of the Industry Concentration Degree Index. In its narrow sense, the degree of industrial concentration is used to express the largest proportion index of the largest entrepreneur among the whole national economy or all the economic activities of enterprises. It is a concept which is used to describe the characteristics of the market structure and the market power of large enterprises. Usually, it is meant by the proportion of the total indexes of several enterprises arranged in the front of one industry among the whole industry. The bigger ratio the is, the higher the industry concentration is. But in its broad sense, the industry concentration can be referred to some industry, some certain owned enterprises, and the proportion of some enterprises in the whole economy. The calculation formula is

$$
C R_{n}=\frac{\sum\left(X_{i}\right)_{n}}{\sum\left(X_{i}\right)_{N}}, \quad N>n,
$$

$C R_{n}$ is the industry concentration of the previous biggest enterprises; $X_{i}$ is the $i$ th enterprise output, production, sales, sales volume, employees number, the total assets, and so on; $n$ is the number of the previous biggest enterprises in the industry; $N$ is the total number of enterprises in the industry.

In this paper, we choose $n=4$ and get the data of industrial concentration in accordance with the data of the "statistical yearbook of Heilongjiang province" in Table 6.

3.2. Analysis of the Industrial Concentration Index. The concentration index of industry (EG index) is to solve the distortion of spatial Gini index, combined with Geffen Dahl $(\mathrm{H})$, proposed by Elilsion and Glaeser [17], a new industrial concentration index which measures the geographical space and reflects the difference of regional economic development. The assumption is as follows: an economy (country or region) in a certain industry with $N$, and $M$ a geographical distribution in the economy area, the calculation formula is

$$
r_{i}=\frac{G_{i}-\left(1-\sum_{j=1}^{M} x_{j}^{2}\right) H_{i}}{\left(1-\sum_{j=1}^{M} x_{j}^{2}\right)\left(1-H_{i}\right)},
$$

where $H_{i}=\sum_{j=1}^{N} z_{j}^{2}, G_{i}=\sum_{j=1}^{M}\left(s_{i j}-x_{j}\right)^{2}$.

$$
r_{i}=\frac{\sum_{j=1}^{M}\left(s_{i j}-x_{j}\right)^{2}-\left(1-\sum_{j=1}^{M} x_{j}^{2}\right) \sum_{j=1}^{N} z_{j}^{2}}{\left(1-\sum_{j=1}^{M} x_{j}^{2}\right)\left(1-\sum_{j=1}^{N} z_{j}^{2}\right)},
$$

$S_{i j}$ is the proportion of which the industry output of industry $i$ in reginal $j$ accounts for national output, $x_{j}$ is the proportion of which all industries output in reginal $j$ accounts for total national output of all industries. $r_{i}$ is the industrial concentration degree of industry $i$, the greater the value of $r_{i}$ is (maximus is 1 ), the more concentrated the industry $i$ is. $G_{i}$ represents a spatial Gini index of industry $i, H_{i}$ is on behalf of the Herfindahl index of industry $i, z_{j}$ is enterprise $j$ in the industrial share of total employment. By the formula in (12), the Heilongjiang province strategic emerging industry industrial agglomeration index is shown in Table 7.

3.3. Analysis of Strategic Emerging Industry Agglomeration in Heilongjiang Province. (1) The degree of industrial concentration of Heilongjiang province in five strategic emerging 
TABLE 6: Strategic emerging industry of Heilongjiang industrial concentration.

\begin{tabular}{cccccc}
\hline Year & New material & Biology & $\begin{array}{c}\text { New energy equipment } \\
\text { manufacturing industry }\end{array}$ & $\begin{array}{c}\text { New farm machinery } \\
\text { and equipment } \\
\text { manufacturing industry }\end{array}$ & $\begin{array}{c}\text { Transportation } \\
\text { equipment } \\
\text { manufacturing industry }\end{array}$ \\
\hline 2008 & 0.325716 & 0.314621 & 0.700157 & 0.311452 & 0.715621 \\
2009 & 0.412326 & 0.378612 & 0.709826 & 0.368610 & 0.778952 \\
2010 & 0.510165 & 0.465365 & 0.714054 & 0.390874 & 0.841048 \\
\hline
\end{tabular}

TABLE 7: Strategic emerging industry of Heilongjiang's industrial agglomeration index.

\begin{tabular}{lccccc}
\hline Year & New material & Biology & $\begin{array}{c}\text { New energy equipment } \\
\text { manufacturing industry }\end{array}$ & $\begin{array}{c}\text { New farm machinery } \\
\text { and equipment } \\
\text { manufacturing industry }\end{array}$ & $\begin{array}{c}\text { Transportation } \\
\text { equipment } \\
\text { manufacturing industry }\end{array}$ \\
\hline 2008 & 0.210071 & 0.063821 & 0.09072 & 0.031925 & 0.227509 \\
2009 & 0.241346 & 0.069672 & 0.141869 & 0.059078 & 0.266527 \\
2010 & 0.289908 & 0.086536 & 0.189489 & 0.120672 & 0.293065 \\
\hline
\end{tabular}

industries and its industry aggregation index are showing a rising trend, but the agglomeration level is not high; the scope of $C R_{n}$ is $0.314621-0.841048$, and the highest amplification of industrial concentration is the advanced material, annual amplification mean reaches, which is closely related with the lower economic development in Heilongjiang province which is located in the frontier of the motherland, the overall level of economic development is not high. As for the advanced material, one kind of emerging industry has the same starting point in different provinces. Therefore, Heilongjiang province developed this area faster, but the industrial concentration is not very high, reached 0.510165 in 2010, which required us to invest more in a high level and increase its concentration ratio. Among them, the industry concentration of transportation equipment manufacturing industry concentration degree index was the highest, reached 0.841048 in 2010 , which fitted the rapid development of transportation equipment manufacturing industry trend in recent years. Therefore, our province should concentrate more on strength, seize the opportunity, depend on the relatively strong foundation of equipment manufacturing industry, and focus on supporting the potential of the transportation equipment manufacturing industry, which results in the rapid development.

(2) The degree of industrial concentration of Heilongjiang province is normally low, only reached 0.031925-0.293065 and all less than 0.3 , which declares that the Heilongjiang province, which has advantage in agriculture, states in a weaker area comparing to other provinces. And its agriculture machinery equipment manufacture's concentration index is only 0.120672 , which declares that its productivity of agriculture machinery equipment manufacture is very poor, which cannot fit the demand of modern agriculture productivity. However, the greatest increasing trend is gratifying, which separately reached $45.9 \%$ and $104.3 \%$ of the two years. It also means that the Heilongjiang province has realized the importance and feasibility to develop the new kind of agriculture machinery equipment manufacture. The concentration index of biological industry is low, because the biological industry belongs to the resource intensive industries the phenomenon of all over the country repeat construction is pretty serious, which is more difficult to form in a particular province of industrial agglomeration. New material industry and new energy equipment manufacturing's industry concentrations have increased steadily, thanks to the advantage of abundant resources in Heilongjiang province.

\section{Conclusion}

Though the policy support is essential to strategic emerging industry, to achieve the objective of adaptation to local conditions, upgrading of industrial structure, and rapid and healthy economic development, it is very important to choose the suitable industry according to the characteristics, level, and realistic situation. In this paper, improved DEMATEL model based on input-output and complex network theory is adopted, which can play a comprehensive evaluation effect, by fully relying on the advantages of traditional industries and fully considering the coupling relationship between them. Taking Heilongjiang province as an example to choose 2007 input-output analysis of regional strategic emerging industry, the selection results are basically the same with the "12th Five-Year Plan" in 2011. The results can show that the the selection and model analysis are in conformity with the development reality and reflect its science, objectivity, and reasonableness. In addition, a dynamic follow-up index test on industry concentration and aggregation is established with the industrial development data from 2008 to 2010. Considering the sustainable development of strategic emerging industry, the ecoefficiency and dynamic industrial evaluation will be continued in the future. 


\section{Acknowledgments}

This research was partially supported by the National Natural Science Foundation of China (Grant nos. 71173060, 71102131), the Social Sciences Foundation of Heilongjiang Province (project no. 10E078), the National Natural Science Foundation of Heilongjiang Province (Grant nos. G201004), and the Social Science research Foundation of Heilongjiang Province Education Department (project no. 12512278).

\section{References}

[1] Premier Jiabao Wen, "Government Work Report," China Network, 2012, http://www.china.com.cn/.

[2] L. Q. Guo, "International Comparison and Enlightenment in the adjustment of the declining industry," Economic Review, vol. 4, pp. 14-16, 2004.

[3] F. L. Qiao and J. Yang, "Research on selection and evaluation of strategic emerging industry in Liaoning Province," Journal of Shenyang University of Technology, vol. 4, pp. 268-273, 2010.

[4] Y. Q. Xiong and D. Zeng, "The cultivation and development of strategic emerging industries: based on the perspective of the traditional industries," Emerging Industry Research, vol. 4, pp. 49-54, 2011.

[5] Z. C. He, "Strategic emerging industry choice and evaluation and empirical analysis," Public Understand Science, vol. 12, pp. 62-67, 2010.

[6] H. M. Li, "Regional strategic emerging industry selection evaluation," Journal of North China Water Conservancy and Hydropower College (Social Sciences Edition), vol. 4, pp. 91-93, 2011.

[7] D. S. Luo, "The establishment of evaluation index system of industrial characteristics and thinking based," Journal of City Economy, vol. 1, pp. 7-9, 2012.

[8] Z. H. Hu, C. Q. Li, and X. Y. Qing, "Based on the AHP-IE-PCA 'combination weighting method of strategic emerging industry selection model,' Public Understand Science, vol. 7, pp. 104-110, 2011.

[9] Z. Y. Liu and H. S. Cheng, "Strategic emerging industry cluster development and network characteristics," Reform, vol. 5, pp. 36-42, 2010.

[10] Y. Liu, "Experience and Enlightenment of Japan in the development of strategic emerging industries," City Development Strategy, vol. 6, pp. 2-25, 2010.

[11] Y. C. Ao and J. X. Liu, "Theoretical thoughts of the selection of regional strategic new industries," The Commercial Era, vol. 21, pp. 116-117, 2012.

[12] Z. L. Xing, "Study on regional industrial structure network model based on complex network theory," Industrial Technology and Economy, vol. 2, pp. 19-30, 2012.

[13] R. Liu and Z. F. Zhou, "Study on the evaluation index system of credit risks of enterprise based on DEMATEL," Management Experts Academic Edition, vol. 1, pp. 22-30, 2012.

[14] G. Tzeng, C. Chiang, and C. Li, "Evaluating intertwined effects in e-learning programs: a novel hybrid MCDM model based on factor analysis and DEMATEL," Expert Systems with Applications, vol. 32, no. 4, pp. 1028-1044, 2007.

[15] Y. K. Liang and Z. D. Ma, "Construction risk analysis of foundation engineering based on DEMATEL method," Journal of Engineering Management, vol. 2, pp. 164-167, 2010.

[16] C. Y. Zhu and M. S. Yang, "Modifying the importance ratings of customers' requirements correction based on DEMATEL and
Entropy," Industrial Engineering and Management, vol. 2, pp. $97-$ 101, 2012.

[17] G. Ellison and E. L. Glaeser, "Geographic concentration in U.S. manufacturing industries:a dartboard approach," Journal of Political Economy, vol. 105, pp. 889-927, 1997. 


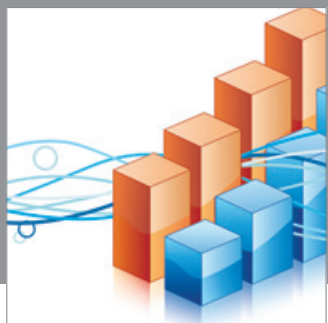

Advances in

Operations Research

mansans

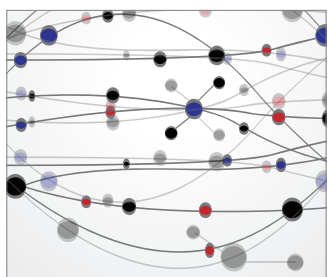

The Scientific World Journal
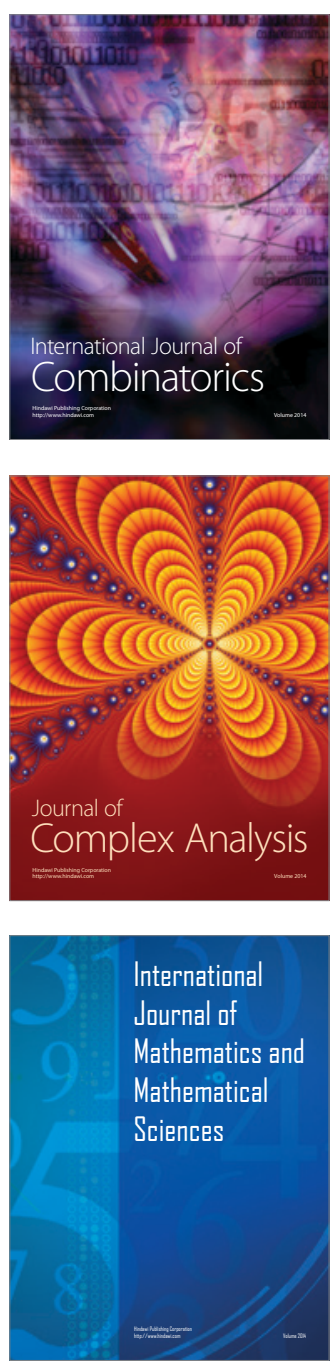
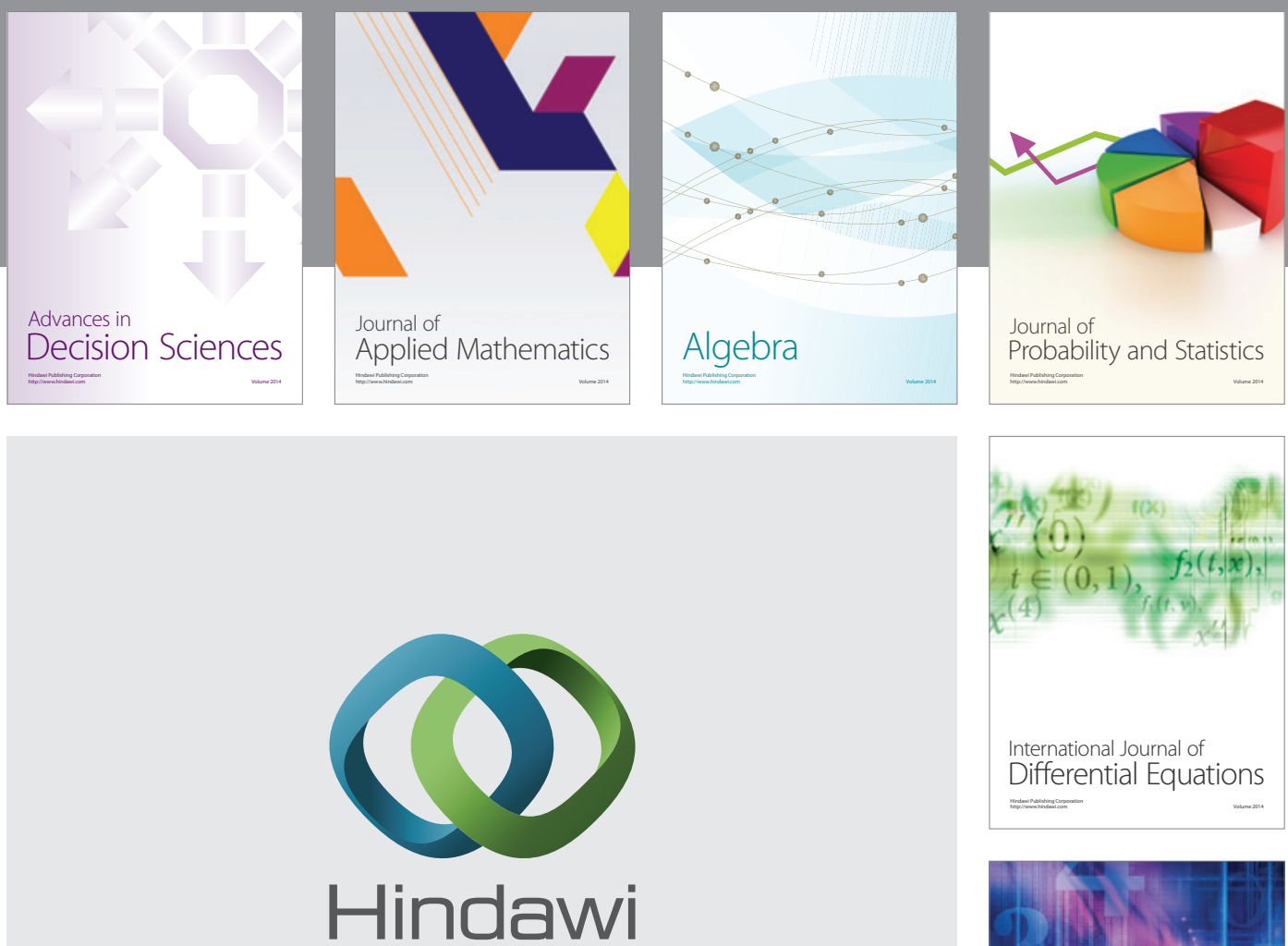

Submit your manuscripts at http://www.hindawi.com
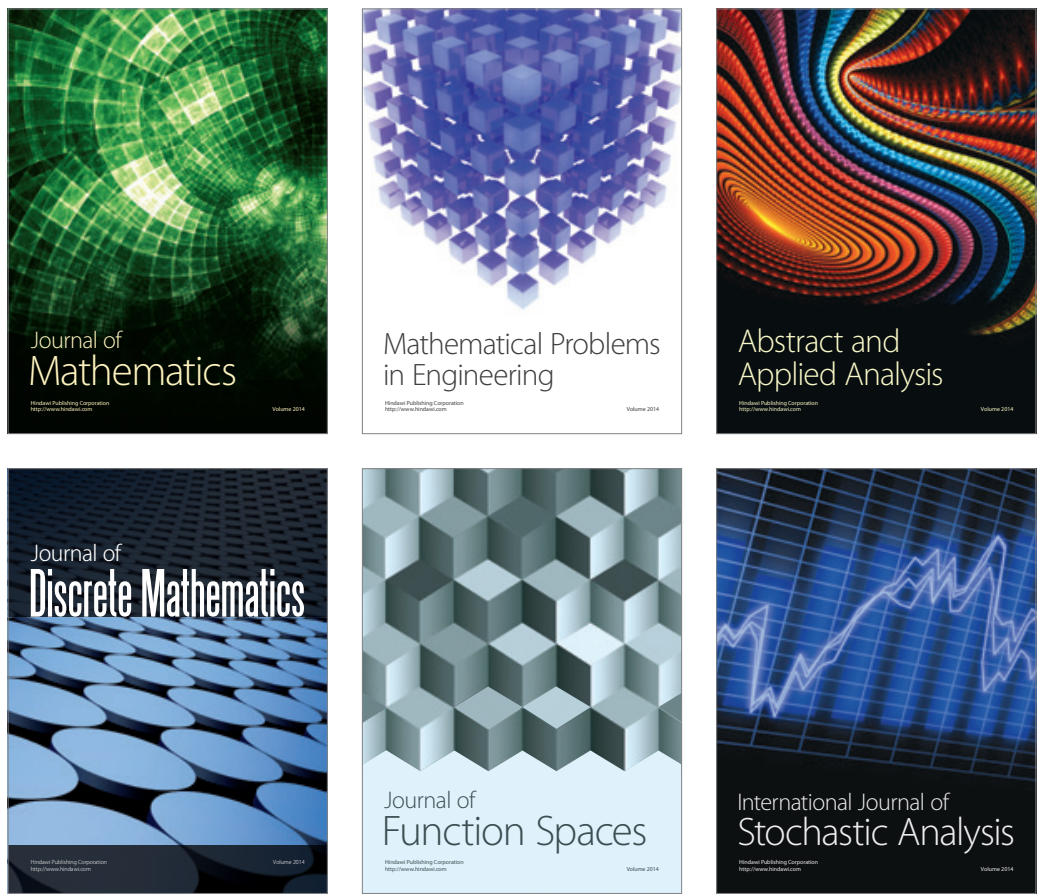

Journal of

Function Spaces

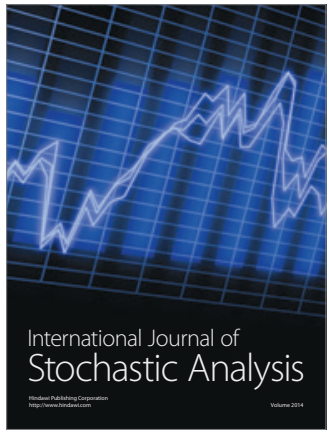

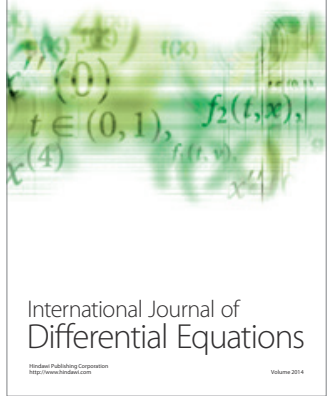
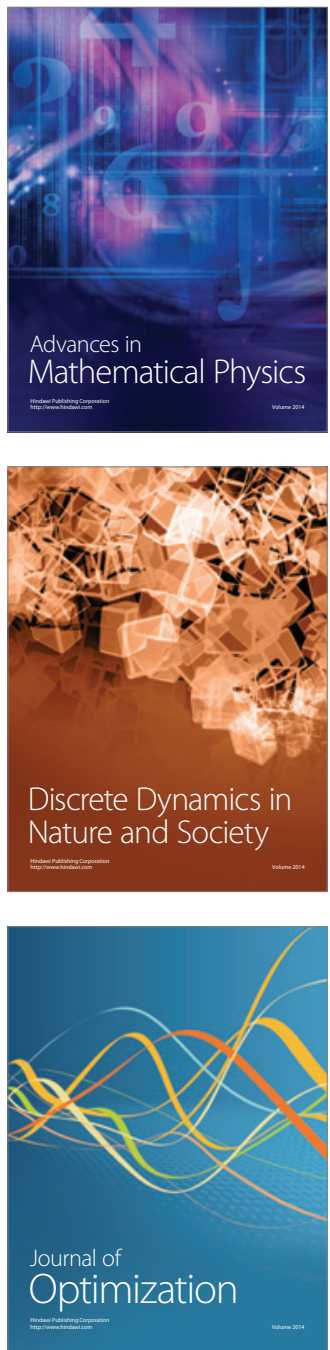